\title{
Sulfidic Mine Wastes at Wodgina - Assessment of the Current Waste Rock Dump Design
}

\author{
C.M. Linklater ANSTO Minerals, Australia
}

A.M. Garvie ANSTO Minerals, Australia

M.J. Comarmond ANSTO Minerals, Australia

M. Walsh Sons of Gwalia, Wodgina Operations, Australia

\section{$1 \quad$ INTRODUCTION}

\subsection{General Background}

The Wodgina tantalum mine is located approximately $120 \mathrm{~km}$ to the south of Port Hedland (Figure 1); it is one of the two largest tantalum mines in the world. The Wodgina ore consists of folded pegmatite sills and dykes hosted within a sequence of metasediments consisting largely of greywacke. Processing of the ore on site consists of crushing, milling and non-chemical gravity separation techniques to produce a $10 \%$ tantalum concentrate. Mining practice is conventional drilling and blasting of 10 metre benches with loading and hauling being carried out conventionally with an excavator and truck fleet.

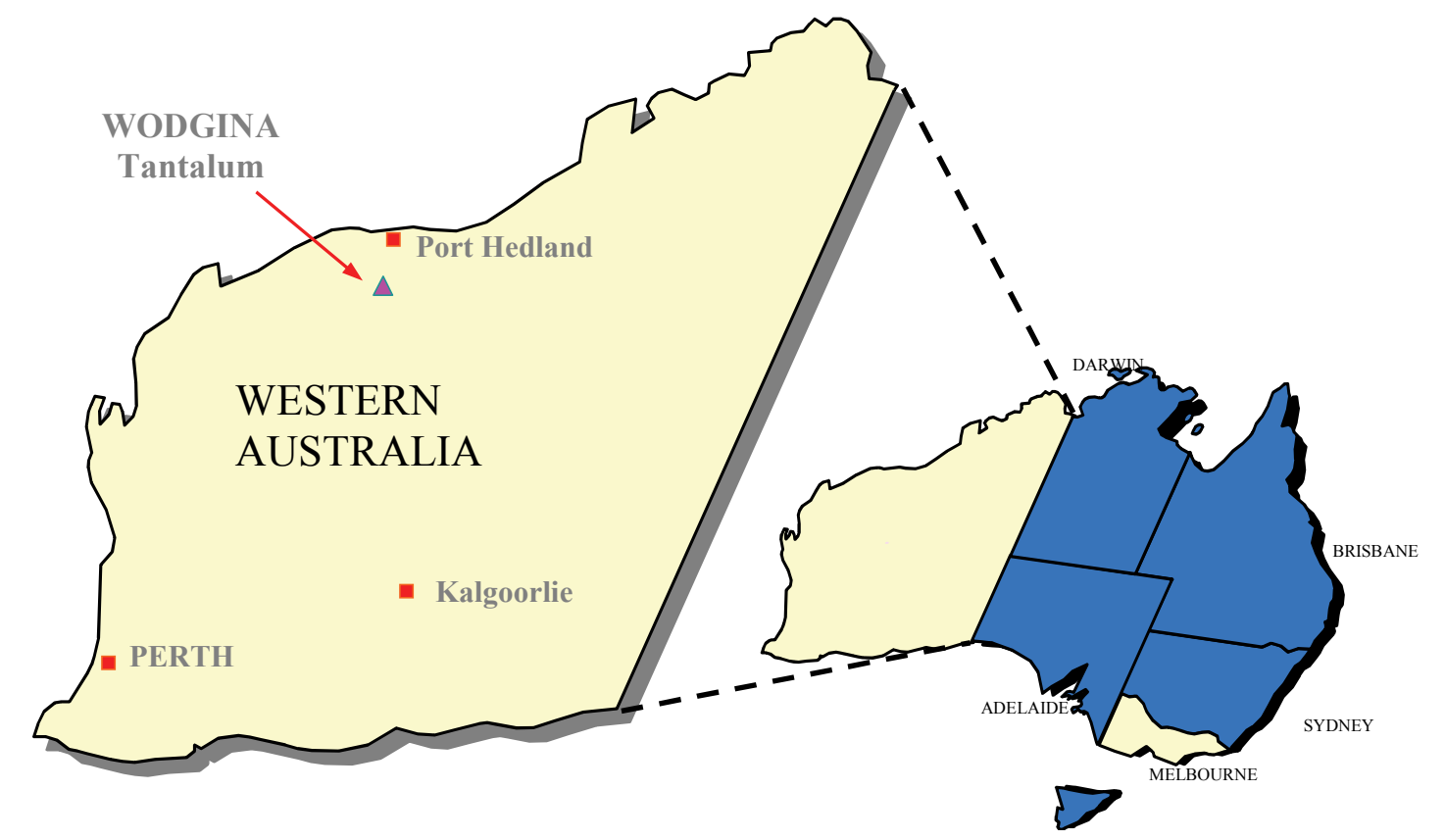

Figure 1 Map showing the location of the Wodgina tantalum mine, Western Australia

The climate at Wodgina is hot and dry. Most rain falls during the summer months and the winters are dry. The mean yearly rainfall is $350 \mathrm{~mm}$ and the mean evaporation rate is $3000 \mathrm{~mm}$. As with most areas of the Pilbara, annual rainfall is highly variable; total annual rainfall ranging anywhere from $100 \mathrm{~mm}$ to $600 \mathrm{~mm}$ should be regarded as normal.

Thrusting and variable weathering have produced a steep topography with steep sided rocky, scree slopes forming $150 \mathrm{~m}$ high hills and valleys in the area of the mine. The area is drained by a number of small ephemeral creeks which all drain into the Turner River (which is itself ephemeral). Groundwater is limited in extent and generally confined to fractured rock aquifers containing fresh to brackish water. 
Vegetation is dominated by spinifex grasses and sparsely distributed small eucalypts. A vegetation survey collected 250 specimens of local plants, and identified no rare or endangered species in the general area of the mine. The dominant land-users in the area are pastoralists and miners.

\subsection{Characteristics of the Waste Rock}

Wodgina produces approximately 10 million tonnes of waste each year, occupying approximately 5 million cubic metres of waste dump volume. Currently, waste rock is disposed of in a dump known as the Eastern Waste Landform. The final dimensions of the waste dump will be approximately $600 \mathrm{~m} \times 1000 \mathrm{~m} \times 60 \mathrm{~m}$ high.

Geochemical characterisation of the waste rock (Environmental Geochemistry International, 2002; Graeme Campbell and Associates, 2005) has indicated that approximately $80 \%$ contains significant sulfur, is potentially acid forming (PAF), and that acid generation is likely to commence shortly after disposal. It is recognised that these materials could pose a problem and the mine continues to develop strategies to control and minimise the risk of detrimental effect on local water quality.

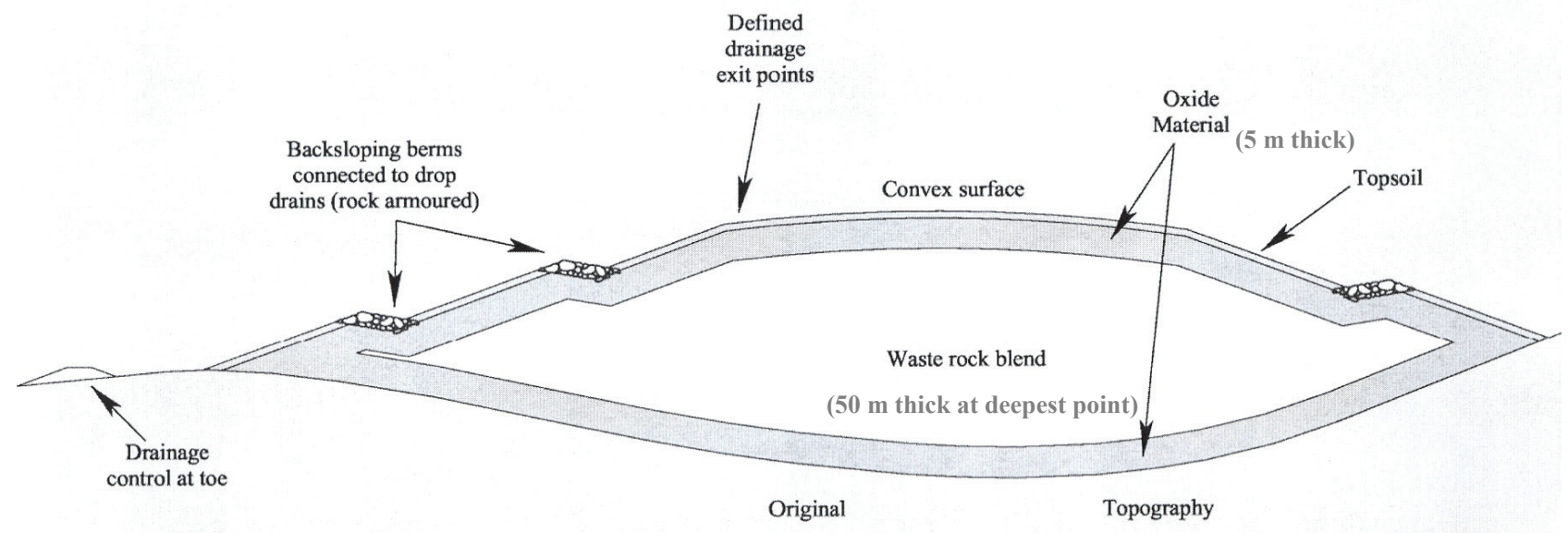

Figure 2 Schematic illustration showing the design of the Eastern Waste Landform (not to scale; final dimensions: $600 \mathrm{~m} \times 1000 \mathrm{~m} \times 60 \mathrm{~m}$ high)

The current design specification for the Eastern Waste Landform includes incorporation of a basal oxide layer (Figure 2). Thus, dump construction involves first placing a layer of oxide material on the ground, then building the sulphide waste rock dump on top of it. Unfortunately, records to support the current design specification are incomplete and the intended purpose of the basal layer has not been stated. Two possible purposes are:

- That the physical properties of the basal oxide layer allow control of water flow at the base of the dump, and allow more efficient collection of dump effluent.

- That the chemical properties of the layer result in retardation of contaminant transport out of the dump, reducing the impact on groundwater.

\subsection{Aims of the Current Study}

The aims of the current study were:

- To understand better the chemical and physical processes controlling contaminant behaviour in the dump (by quantifying the rate at which sulfidic material might oxidise, measuring saturated hydraulic conductivities in the field and assessing the leachability of contaminants from dump materials). 
- To assess the potential benefits that might be offered by the basal oxide layer and determine whether continued inclusion of this layer in the dump design is justified based on the new understanding of the chemical and physical processes in the dump.

Outcomes from the study will help inform future debate as to whether the dump presents a significant risk to the local environment, and what management strategies should be adopted to give the most effective mitigation of any risks posed.

\section{METHODOLOGY}

To meet the aims of the study a work program was designed to furnish data on chemical and physical properties of key dump materials. The following materials were studied:

- Sulfidic waste rock - largely comprising a mixture of greywacke, basalt and shale, and typically light grey in colour. This material is representative of the bulk of material contained within the dump.

- Base oxide - highly weathered near-surface material and soil originally located within the boundary of the open pit; typically red-brown and brown in colour (weathered metasediments), but with localised grey areas (weathered mafic rocks). This material forms the basal layer in the current dump design.

- In-situ oxide - typically red-brown and brown in colour. It is equivalent in many ways to the base oxide material but samples were sourced from the ground immediately underlying the dump footprint.

Mineralogical analyses were not conducted as part of this work. Previous studies of dump sulfide samples (Graeme Campbell and Associates, 2005) indicated that major mineralogical components were the amphibolitic minerals, hornblende and grunerite, while minor and accessory minerals were chlorite, mica and magnetite. The main sulfide present was pyrrhotite, $\mathrm{Fe}_{1-\mathrm{x}} \mathrm{S}$. With respect to the base oxide and in situ oxide materials, limited mineralogical information is available. They are likely to be weathered equivalents of the underlying geology (greywacke, sulfidic shales, basalt and pegmatite). Clays and oxyhydroxides minerals are widespread (almost ubiquitous) products of weathering in soils and almost certainly form significant components of these materials.

For the materials listed above, a number of experimental methods were employed to determine values for some chemical and physical parameters of interest. These methods are described in the following sections. All laboratory methods involved samples crushed to a grain-size less than $3 \mathrm{~mm}$.

\subsection{Measurement of Intrinsic Oxidation Rates (IOR)}

The intrinsic oxidation rate (IOR) is the rate at which a sample consumes oxygen. The IOR was measured in the laboratory by placing a sample in a sealed canister and monitoring the oxygen gas concentration over time. The oxygen profile was used to calculate an oxygen consumption rate. The minimum IOR measurable was dependent, amongst other variables, on changes in sample temperature during the measurement and the duration of the measurement. In this work, measurement periods ranged from 16 to 34 hours. The temperatures during the measurement of each sample varied by less than $+/-0.5^{\circ} \mathrm{C}$ and all measurements were made in the range 16 to $21^{\circ} \mathrm{C}$. The samples were measured 'as received'; no moisture was added.

\subsection{Field Measurement of Hydraulic Conductivity}

A dual ring infiltrometer was constructed and operated following guidelines provided by Reynolds et al., 2002. Measurements were conducted by the Western Geotechnics Group (WGG, 2006) and Wodgina Mine personnel. For each material of interest (sulfidic waste, base oxide and in-situ oxide), measurements were conducted at three different sites. At the different sites, the structure and texture of the surface varied depending on the finishing method: track-rolling by a dozer, compaction by truck traffic, compaction by truck traffic and then lightly graded, and only lightly graded. Grain-size varied from less than a centimetre to particle diameters greater than $15 \mathrm{~cm}$. 
Because the particle sizes were often quite large, the rings used for the field measurements had large diameters: $93.6 \mathrm{~cm}$ and $182.2 \mathrm{~cm}$. The rings were not placed concentrically and were spaced so that flow from one ring would not interfere with flow from the other. The rings were, however, sufficiently close that the materials being tested would have similar characteristics. Water was provided from $1000 \mathrm{~L}$ bulk transport containers, with flow being controlled manually using a valve on the outlet at the base of the container. Figure 3 is a photograph of the equipment used for the measurements.

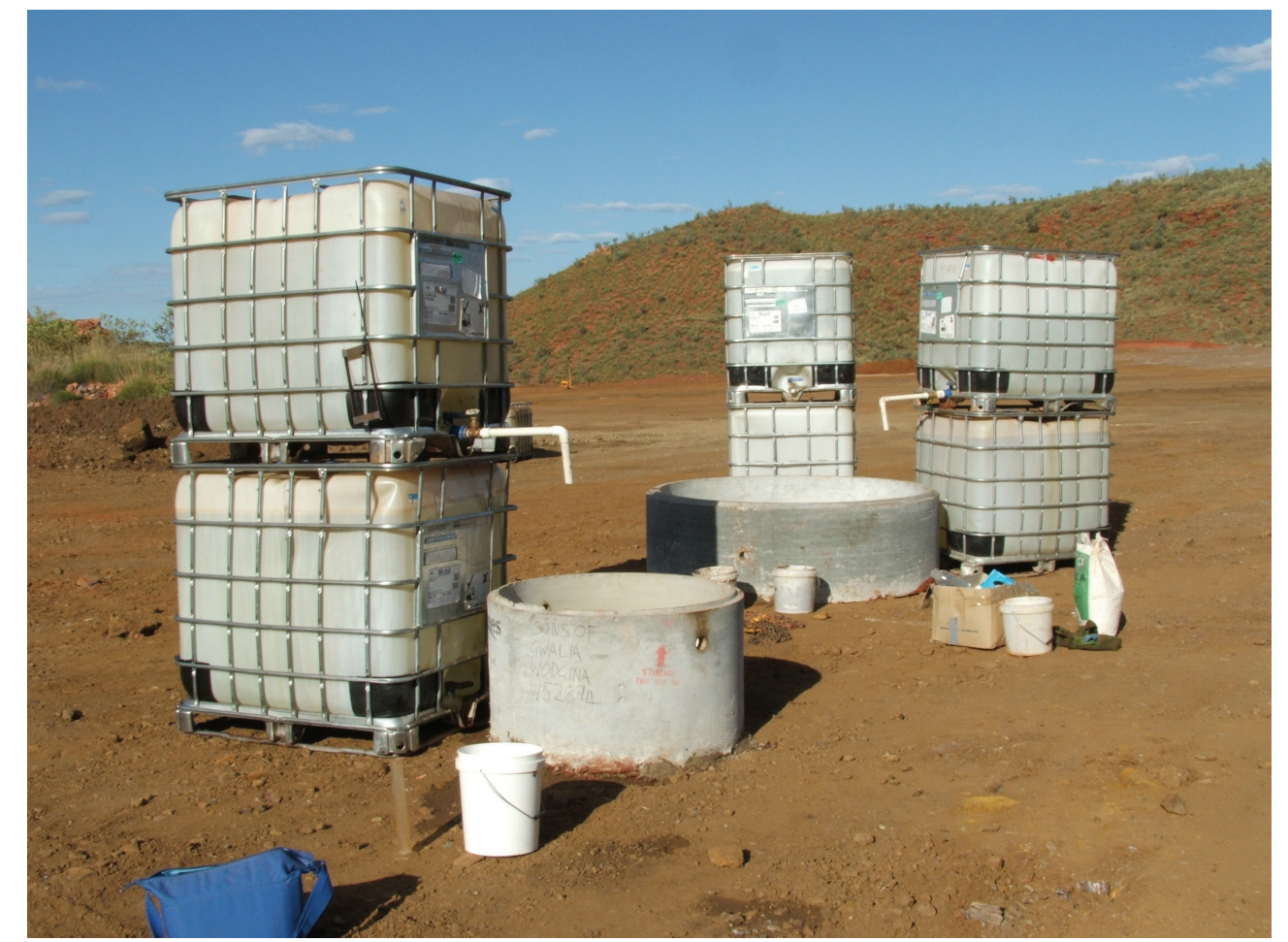

\section{Figure 3 Photograph showing the dual ring infiltrometer equipment in the field}

An approximately constant head of water was maintained within the rings (at a nominal $12 \mathrm{~cm}$ ) and the accumulated volume of water required to achieve this was recorded. The flux of the water (volume of water passing per unit time through a unit cross-sectional area of porous material, perpendicular to the direction of flow) was determined (WGG, 2006). Where possible, the field saturated hydraulic conductivity and a macroscopic capillary length parameter value $\left(\alpha^{*}\right)$ were calculated using the simultaneous equations approach described by Reynolds et al., 2002.

\subsection{Leach Tests}

In leach tests, crushed solid material is contacted with a leach solution of interest. After a defined time period, the solution is removed and analysed to determine whether contaminants have leached from the solid during the test. In the current work, the leach test method was based on Price, 1997. It has been adapted so that results are of most relevance to the circumstances under investigation, namely whether components would leach from Wodgina materials should they be exposed to acidic waters. Two sets of tests were undertaken:

- One set using dilute sulfuric acid $(0.01 \mathrm{M})$, to represent acid waters being generated in the dump.

- One set using de-ionised water, to determine if any of the rock components would leach under nonacidic conditions.

Ten samples were studied: 4 samples of sulfidic waste rock, 3 base oxide samples and 3 in-situ oxide samples. All solid samples were crushed to $<300 \mu \mathrm{m}$. The tests were conducted at a solution : solid ratio of 3:1 (750 ml solution: $250 \mathrm{~g}$ solid). The fine grain-size, along with the low solution : solid ratio, are designed 
to enable collection of meaningful data on a laboratory scale and within a short time frame. The data obtained can be used to indicate which components are more readily leached from the samples and to compare the behaviour of the different materials of interest.

All solutions were prepared using de-ionised (MilliQ) water and high purity concentrated sulfuric acid. Blanks were established by adding $750 \mathrm{~mL}$ of each solution to a reaction vessel and subjecting these vessels to the same conditions as vessels containing solid.

The reaction vessels were agitated gently $(1200 \mathrm{rpm})$ on an orbital shaker for 24 hours. On completion of the 24-hour agitation, the reaction vessels were left to stand for a minimum of 3 hours, allowing any suspended material to settle. Samples of the supernatant were removed, filtered (through a $0.45 \mu \mathrm{m}$ filter) and acidified (to $\mathrm{pH}<2$ using high purity nitric acid) before analysis by inductively coupled plasma - atomic emission spectrometry and inductively coupled plasma - mass spectrometry (ICP-AES and ICP-MS).

\section{$3 \quad$ RESULTS}

\subsection{Oxidation Rates within the Dump Materials}

The measured IOR values range from $<10^{-12} \mathrm{~kg}\left(\mathrm{O}_{2}\right) \mathrm{kg}^{-1} \mathrm{~s}^{-1}$ to $2 \times 10^{-11} \mathrm{~kg}\left(\mathrm{O}_{2}\right) \mathrm{kg}^{-1} \mathrm{~s}^{-1}$ (Table 1). In the Wodgina samples, it is assumed that the main process consuming oxygen is sulfide oxidation. All the measured values are low, being close to or below the limit of detection of the technique $\left(1 \times 10^{-12} \mathrm{~kg}\left(\mathrm{O}_{2}\right) \mathrm{kg}^{-}\right.$ ${ }^{1} \mathrm{~s}^{-1}$ ). The samples 'as received' contained little moisture, often less than $0.5 \mathrm{wt} \%$ (Table 1). The highest moisture contents, $\sim 2 \mathrm{wt} \%$, are observed for oxide materials and probably reflect a higher clay content in these sample types. In the case of relatively dry samples, low IOR values would be expected (sulfide oxidation requires the presence of water). Given the hot, dry climate of the region, it is expected that the material in the dump will be dry for long periods of time. The measured IOR values are therefore directly relevant to conditions expected in the field. It should be pointed out however, that rain will increase the water content of the waste and could lead to an increase in oxidation rates within the dump. Studies of samples from other sites have suggested that adding $10 \mathrm{wt} \%$ water to samples that originally contained negligible moisture can be associated with an increase in the measured IOR value (approaching an order of magnitude).

Table 1 also shows measured values for the total $\mathrm{S}$ content of the samples. As would be expected, higher IOR values are associated with higher total $\mathrm{S}$ contents, typically dump sulfide samples. Interestingly, one of the base oxide samples, BO-04, also has a high $\mathrm{S}$ content, $1.6 \mathrm{wt} \%$. BO-04 is also associated with a relatively high IOR value, $2 \times 10^{-11} \mathrm{~kg}\left(\mathrm{O}_{2}\right) \mathrm{kg}^{-1} \mathrm{~s}^{-1}$. BO-04 is light grey in colour and believed to be a less weathered form of the base oxide material. Additional studies are underway to test if grey-coloured base oxide materials are consistently associated with high S contents and IOR values. 
Table 1 Results of measurements of the intrinsic oxidation rate of the samples

\begin{tabular}{|c|c|c|c|}
\hline Sample & $\begin{array}{c}\text { Moisture content } \\
\text { wt } \% \text { (wet basis) }\end{array}$ & $\begin{array}{c}{ }^{1} \text { Total } S \text { content } \\
(w t \%)\end{array}$ & $\begin{array}{c}\text { Intrinsic oxidation rate } \\
(\mathrm{IOR}), \mathrm{kg}_{\left(\mathrm{O}_{2}\right) \mathrm{kg}^{-1} \mathrm{~s}^{-1}}\end{array}$ \\
\hline \multicolumn{4}{|c|}{ Dump sulfide materials } \\
\hline DS-01 & 0.2 & 1.7 & $2 \times 10^{-11}$ \\
\hline DS-02 & 0.1 & 1.3 & $1 \times 10^{-11}$ \\
\hline DS-03 & 0.1 & 0.6 & $8 \times 10^{-12}$ \\
\hline DS-04 & 0.2 & 1.5 & $2 \times 10^{-11}$ \\
\hline \multicolumn{4}{|l|}{ Base oxides } \\
\hline BO-01 & 0.6 & $<0.1$ & $<10^{-12}$ \\
\hline BO-02 & 2.1 & 0.1 & $3 \times 10^{-12}$ \\
\hline BO-04 & 2.1 & 1.6 & $2 \times 10^{-11}$ \\
\hline \multicolumn{4}{|l|}{ In-situ oxides } \\
\hline IO-01 & 1.6 & $<0.1$ & $2 \times 10^{-12}$ \\
\hline IO-02 & 0.4 & $<0.1$ & $<10^{-12}$ \\
\hline IO-04 & 0.3 & $<0.1$ & $2 \times 10^{-12}$ \\
\hline
\end{tabular}

Note 1 Total sulfur was measured by Leco following pulverisation of the sample

\subsection{Saturated Hydraulic Conductivity of Dump Materials}

Calculated field-saturated hydraulic conductivities $\left(\mathrm{K}_{\mathrm{fs}}\right)$ and macroscopic capillary length parameter values $\left(\alpha^{*}\right)$ values are presented in Table 2 . The measured saturated hydraulic conductivity values range from $4.4 \times$ $10^{-5} \mathrm{~cm} / \mathrm{s}$ (one of the base oxide sites) to $3.7 \times 10^{-2} \mathrm{~cm} / \mathrm{s}$ (one of the dump sulfide sites). At five of the nine sites studied, it was not possible to calculate physically realistic values of $\alpha^{*}$ from the data collected. For the remaining sites, $\alpha^{*}$ values ranged from 0.02 to 0.1 .

The measured hydraulic properties are quite variable and do not show a discernible relationship with material type.

Table 2 Hydraulic properties of dump materials

\begin{tabular}{|l|c|c|}
\hline Test Site & $\mathbf{K}_{\mathrm{fs}}(\mathbf{c m} / \mathbf{s})$ & $\boldsymbol{\alpha}^{*} \mathbf{( 1 / \mathbf { c m } )}$ \\
\hline Dump sulfide materials & $3.7 \times 10^{-2}$ & 0.07 \\
\hline S1 & ${ }^{(2)} 2.5 \times 10^{-4}$ & ${ }^{(1)}$ \\
\hline S2 & ${ }^{(2)} 1.6 \times 10^{-4}$ & 0.02 \\
\hline S3 & $4.4 \times 10^{-5}$ & 0.03 \\
\hline Base oxides & $1.1 \times 10^{-4}$ & $(1)$ \\
\hline O1 & ${ }^{(2)} 1.2 \times 10^{-3}$ & ${ }^{(1)}$ \\
\hline O2 & \multicolumn{2}{|c|}{} \\
\hline O3 & ${ }^{(2)} 2.8 \times 10^{-3}$ & ${ }^{(1)}$ \\
\hline In-situ oxides & ${ }^{(2)} 2.0 \times 10^{-4}$ & 0.1 \\
\hline ISO1 & $1.6 \times 10^{-3}$ & \\
\hline ISO2 &
\end{tabular}

Note 1 Method did not produce physically realistic values of $\alpha^{*}$

Note 2 Where unrealistic values of $\alpha^{*}$ were obtained it was assumed that the $\mathrm{K}_{\mathrm{fs}}$ value calculated using Reynolds equations was not accurate. In these cases, the average of the values measured using the two rings was used. 
Based on measured rainfall data collected at the Wodgina minesite, maximum rainfall intensities for the years 2003, 2004 and 2005 were $1.11 \times 10^{-3}, 3.89 \times 10^{-3}$ and $1.44 \times 10^{-3} \mathrm{~cm} / \mathrm{s}$, respectively. Such intense rainfall events, however, were extremely rare, and the average rainfall intensities for the same three years were $1.24 \times 10^{-6}, 1.19 \times 10^{-6}$ and $6.6 \times 10^{-7} \mathrm{~cm} / \mathrm{s}$, respectively. In general, rainfall intensities are smaller than the measured saturated hydraulic conductivities, suggesting that, if evaporation is ignored, most water incident on exposed dump surfaces (typically comprising dump sulfide material) will infiltrate downwards rather than pool on the surface.

The hydraulic properties of the base oxide and in-situ oxide are similar to the dump sulfides. Thus, for a case where water flux in the dump is uniform, it is likely that infiltrating water will continue to travel downwards, rather than pool at interfaces between the different material types. Non-uniform water flow might arise due to (i) material inhomogeneity, for example related to variation in the degree of compaction or (ii) macropore flow of water within the dump. Material inhomogeneity might cause local changes in water flow direction. For example, on encountering a region of low hydraulic conductivity, one might expect local pooling and development of lateral flow across the surface of this region. However, if the low hydraulic conductivity region is laterally discontinuous, downward flow will resume as soon as a region of higher hydraulic conductivity is encountered. Macropore flow might be expected during extreme rainfall events, but is believed to account for only a small proportion of the total volume of water, less than $10 \%$ (Nicol, 2002).

\subsection{Contaminant Leachability}

Figures 4 and 5 show the concentrations of selected minor/trace elements as measured in the solutions at the end of the leach period (analyses of the final solutions included a wide spectrum of elements; only those elements present in detectable quantities are discussed here). Dilute sulfuric acid is a relatively aggressive leach solution and, as expected, greater concentrations of most of the elements were measured in these tests rather than in the tests involving de-ionised water. For most of the elements studied, leached concentrations were less than $100 \mu \mathrm{g} / \mathrm{L}$. Exceptions are:

- Half the transition metals shown in Figure 4 (in particular, Fe, Mn and Ni but also Co and $\mathrm{Zn}$ ). Concentrations of these metals in the leachate can be in excess of $10,000 \mu \mathrm{g} / \mathrm{L}$, especially under acidic conditions.

- $\mathrm{Sr}, \mathrm{Be}, \mathrm{As}$ and Nd (Figure 5). Concentrations of these elements in the leachate often exceed $100 \mu \mathrm{g} / \mathrm{L}$, but rarely exceed $1000 \mu \mathrm{g} / \mathrm{L}$. As and $\mathrm{Nd}$ only exceed $100 \mu \mathrm{g} / \mathrm{L}$ under acidic conditions.

For many elements (e.g. Fe, Mn, Ni, Zn, As), higher concentrations are associated with the dump sulfide samples. Possibly, these elements were present as either major components or impurities in the sulfide minerals (mainly pyrrhotite). Their release during the leach test could indicate the presence of alteration products, perhaps due to prior sulfide oxidation. [It is not expected that significant oxidation would take place during the leach tests, due to the short duration of the tests and the low solubility of oxygen in water.] It is notable that the base oxide sample, BO-04, is associated with the highest leached concentration of a wide range of the elements studied. In fact, based on the data shown in Figures 4 and 5, this sample would be of most concern with respect to metal release. As already mentioned, this sample is believed to be a less weathered form of the base oxide material and further study is underway to determine its chemical properties.

The leach tests were conducted under conditions that cannot be easily extrapolated to the field. The grainsize of the material had been modified and a number of the other experimental conditions may not be representative of conditions in the field (e.g. the water chemistry, the solution : solid ratio). To assess accurately the conditions in the field, detailed hydrologeological and geochemical data are necessary (e.g. to facilitate estimation of the amount of contact between reactive mineral surfaces and flowing water, water residence times, field $\mathrm{pH}$ and redox conditions). These data are not available. Nevertheless, results from the leach tests can be used qualitatively as an indicator of those elements that could be of environmental concern under acidic conditions. These include: $\mathrm{Fe}, \mathrm{Mn}, \mathrm{As}, \mathrm{Be}, \mathrm{Cd}, \mathrm{Co}, \mathrm{Cr}, \mathrm{Cu}, \mathrm{Ni}, \mathrm{Pb}, \mathrm{U}, \mathrm{V}$ and $\mathrm{Zn}$. 


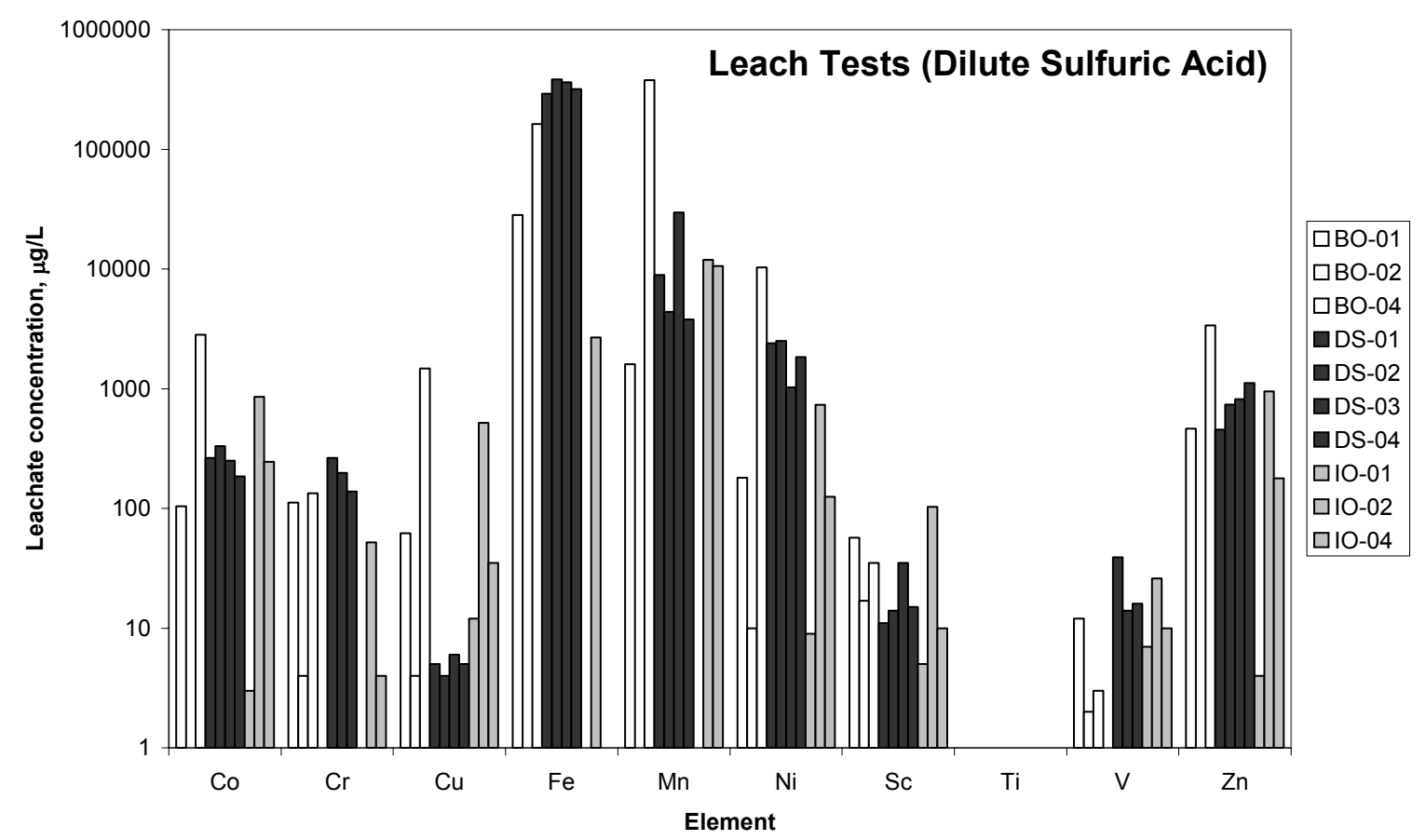

Figure $4 \quad$ Concentrations ( $\mu \mathrm{g} / \mathrm{L}$ ) of transition metals measured in solutions at the end of the leach period (24 hours). In the sample nomenclature, BO-, DS- and IOdenote base oxide, dump sulfide, and in-situ oxide, respectively

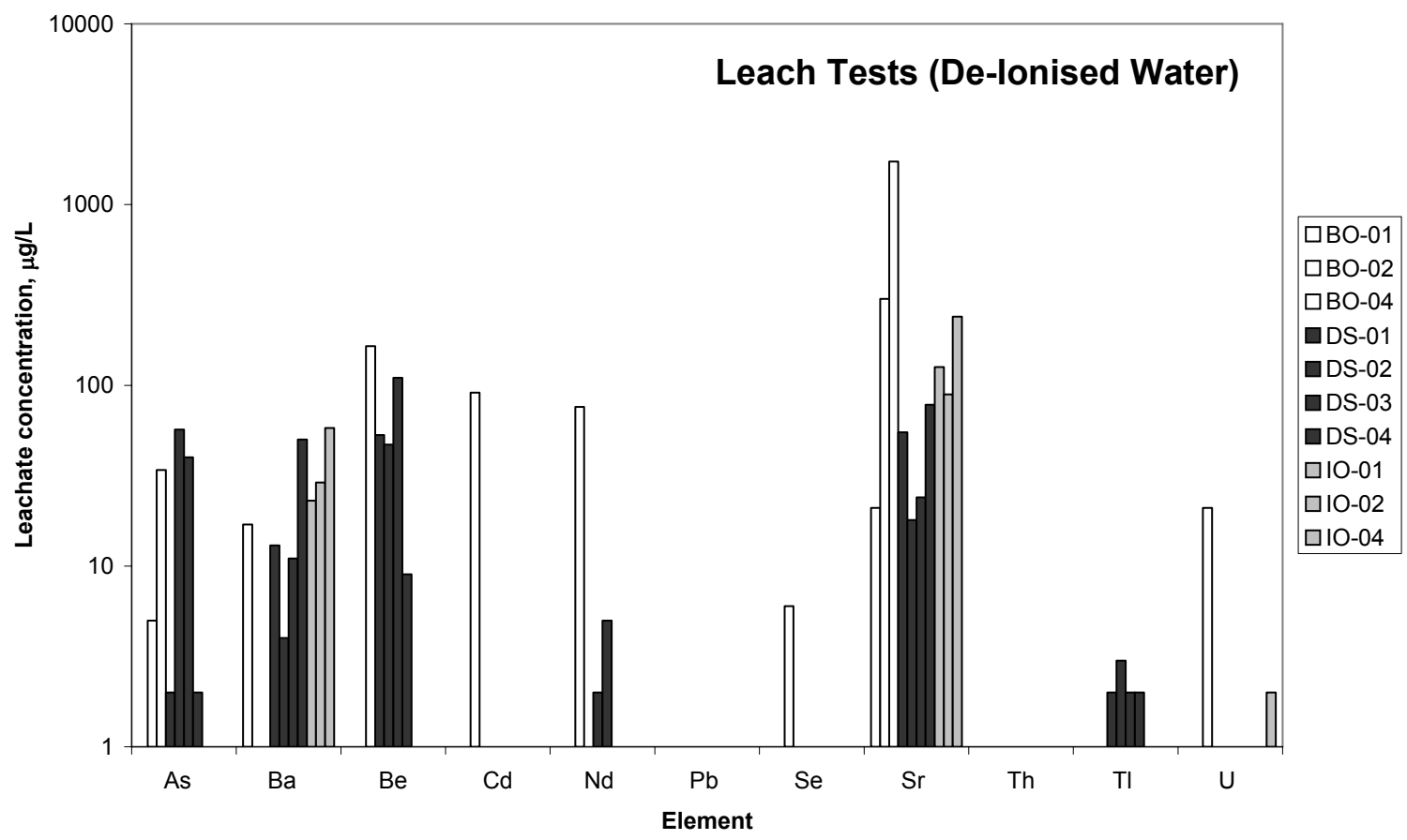

Figure $5 \quad$ Concentrations ( $\mu \mathrm{g} / \mathrm{L}$ ) of miscellaneous trace metals and metalloids measured in solutions at the end of the leach period ( 24 hours). In the sample nomenclature, BO-, DS- and IO- denote base oxide, dump sulfide, and in-situ oxide, respectively 


\section{DISCUSSION}

Using the measured oxidation rates for dump materials (Table 1), it is possible to calculate annual sulfate generation rates for the Eastern Waste Landform. In the current study, these calculations were based on the constant intrinsic oxidation rate model (Gibson et al., 1994). A number of assumptions were necessary:

- That gas transport in the dump was dominated by diffusion.

- The dry bulk density of the dump material was $1.9 \times 10^{3} \mathrm{~kg} \mathrm{~m}^{-3}$; the oxygen diffusion coefficient was $5 \times 10^{-6} \mathrm{~m}^{2} \mathrm{~s}^{-1}$ and the oxygen concentration in air was $0.265 \mathrm{~kg} \mathrm{~m}^{-3}$.

For the Eastern Waste Landform, annual sulfate generation rates of around 150 tonnes of $\mathrm{SO}_{4}$ per hectare were calculated. This value lies towards the low end of a range calculated for waste rock dumps on other sites (from $<10$ to 1100 tonnes of $\mathrm{SO}_{4}$ per hectare, unpublished data). However, it should be pointed out that if advection proved to be an important influence on gas transport within the Eastern Waste Landform, then a higher sulfate generation rate would be expected (due to more rapid transport of gas, and thus a more widespread availability of oxygen). It is also possible that sulfate generation rates could be higher due to higher oxidation rates as a result of wetting by rain.

As well as release of contaminants contained in the sulfide matrix, sulfide oxidation within the dump will result in the development of acidic conditions in infiltrating waters. The leach tests have indicated that higher concentrations of a range of contaminants can be expected under acidic conditions. It has been shown that some of the dump materials have the capacity to neutralise acidity (Environmental Geochemistry International, 2002; Graeme Campbell and Associates, 2005). However, there are not enough data at the current time to estimate the long-term evolution of $\mathrm{pH}$ in dump pore waters and effluent.

Measurement of the hydraulic properties of the dump materials suggests that any water that infiltrates the top surface of the dump will travel downwards, pass through the basal oxide layer and seep into the underlying ground. There is no evidence to suggest that the presence of the basal oxide will alter water flow directions, or reduce the overall flux into the ground. Contaminants carried by the water will therefore be transported downwards. It is worth giving some consideration to whether contaminants will be transported at the same rate as the water. Many contaminants form charged species in solution. Interaction of these charged species with contacting mineral surfaces can slow contaminant migration. Examples of such interactions are surface complexation (adsorption of charged species onto charged mineral surfaces) and ion exchange (ions in solution exchanging for ions present in the mineral lattice). Minerals associated with a strong capacity to interact with solution species are iron oxyhydroxides and clays. Even when present in low quantities by mass, these mineral types can exert a strong control on contaminant mobility.

Iron oxyhydroxides and clays, being common weathering products, could be present in small quantities in all the Eastern Waste Landform materials. However, they are likely to be significant components of the base oxide and in-situ oxide materials. It is possible, therefore, that contaminant mobility will be low in these materials. Based on available information, it is not possible to assess whether contaminants will be more or less mobile in the base oxide layer than in the underlying ground. The base oxide layer may offer a benefit to the overall dump design by retarding migration of contaminants from the dump into the underlying ground. However, it could be argued that contaminant transport would be retarded whether or not the basal oxide layer was present, and that the basal oxide layer does not therefore offer a significant benefit. This argument is particularly strong if the groundwater table, or any sensitive receiving environment, lies at some significant distance from the dump base.

In the Introduction, two possible functions for the base layer were proposed: (i) that the physical properties of the base oxide layer exert some control on the direction of water flow in the dump or (ii) that the chemical properties of the layer result in retardation of contaminant transport out of the dump. Based on the preceding discussion, the materials currently being utilised in dump construction are not consistent with either of these functions being particularly effective. For the first of these functions to be effective, the basal layer would have to have a very low saturated hydraulic conductivity, so that water flow was diverted laterally along its surface. Alternatively, if the saturated hydraulic conductivity of the base oxide layer was relatively high (or at least, higher than the underlying ground) then water flow could be diverted laterally and flow within the base oxide layer to exit at the toe of the dump. It is possible that some improved performance is attained via the second function, but it is not clear that the improvement is significant, especially given that the 
underlying ground may carry out a similar function. It has also been noted that the base oxide material itself may represent a source of contamination (one of the samples included in the current study, BO-04, was associated with high leachable concentrations for a range of contaminants).

Based on the preceding discussion, more work is necessary to establish whether the dump does pose a threat to the local water quality and which management strategies could give more effective mitigation of the risks posed. A valuable precursor to such work would be an assessment of the proximity of local sensitive ecosystems and their degree of tolerance with respect to potential contaminants. Past and present water quality should also be assessed to provide a baseline for future comparisons. Such assessments would allow stakeholders to identify appropriate performance requirements for the dump, helping guide selection of appropriate dump designs and effective monitoring regimes.

\section{CONCLUSIONS}

Measurements of oxidation rates for key dump materials, combined with results from leach testwork, suggest that contaminants may pose a threat to local water quality. Sorption processes are expected to limit the mobility of contaminants, particularly within the base oxide layer and the underlying ground, suggesting that any impacts will be proximal to the dump in the short term.

At the proposed site of the waste dump, the physical and chemical properties of the underlying ground are very similar to those of the artificially constructed base oxide layer. The measured saturated hydraulic conductivities are similar, and both materials have the potential to neutralise acid and retard contaminants. It is concluded therefore that, for the sites that were tested, the basal oxide layer does not provide any significant benefits when compared to the underlying ground.

Looking forward, the focus should be towards further quantification of acid generation and/or contaminant release from the dump materials with a view to:

- Confirming whether or not dump effluent quality is of environmental concern, now or in the future.

- Developing dump designs aimed at more effective control and mitigation of contaminant generating processes (e.g. reducing oxygen/water infiltration into dump, minimising dump seepage).

Assessments of potential dump designs should be made with reference to performance targets agreed by stakeholders (regulators, local community, mine operators, etc).

\section{ACKNOWLEDGEMENTS}

The hydraulic conductivity measurements presented in this work were undertaken by Western Geotechnics Group. Amy Walsh provided valuable assistance in the development and implementation of the field methodology. Patricia Gadd and Chris Chipeta are gratefully acknowledged for providing laboratory and analytical support for the work.

\section{REFERENCES}

ANZECC/ARMCANZ (2000) An introduction to the Australian and New Zealand guidelines for fresh and marine water quality.

Environmental Geochemistry International Pty Ltd (2002) Review of the acid forming characteristics of water rock and implications for waste rock management, Document No. 2907/570, Report to Sons of Gwalia, Wodgina Mine.

Gibson, D.K., Pantelis, G. and Ritchie, A.I.M. (1994) The relevance of the intrinsic oxidation rate to the evolution of polluted drainage from a pyrite waste rock dump. Proc. Int. Conf. Abatement Acid Drainage, Pittsburg, Pennsylvania.

Graeme Campbell and Associates Pty Ltd (2005) Weathering behaviour of waste-bedrock samples, Job No. 0442 , Report to Sons of Gwalia, Wodgina Mine.

Nichol, C. (2002) Transient flow and transport in unsaturated heterogeneous media: field experiments in mine waste rock. PhD Thesis, University of British Columbia, Vancouver, British Columbia. 
Price, W.A (1997) Guidelines and recommended methods for the prediction of metal leaching and acid rock drainage at minesites in British Columbia, Draft Report, Reclamation Section, energy and Minerals division, Ministry of Employment and Investment, British Columbia, 1997.

Reynolds, W.D., Erlick, D.E., Youngs, E.G., Amoozegar, A. and Bouma, J. (2002) Chapter 3 In: Methods of Soil Analysis Part 4 Physical Methods, Soil Sci. Soc. A. Eds Dane and Clarke Topp.

Western Geotechnics Group (2006) Report on Infiltrometer Testing - Wodgina Mine Site, Project no. 60-8105, May 2006. 